ТЕЧЕНИЕ ТРОМБОЗА ГЛУБОКИХ ВЕН НИЖНИХ КОНЕЧНОСТЕЙ В ОСТРОМ ПЕРИОДЕ НА ФОНЕ АНТИКОАГУЛЯНТНОЙ ТЕРАПИИ В ЗАВИСИМОСТИ ОТ СОДЕРЖАНИЯ D-ДИМЕРОВ И С-РЕАКТИВНОГО БЕЛКА

(C) А.С. Петриков ${ }^{1,2}$, Д.В. Дудин ${ }^{1,3}$, Л.Н. Попкова ${ }^{3}$, И.В. Володин ${ }^{1,3}$, Я.Н. Шойхет ${ }^{1,3}$

Алтайский государственный медицинский университет, г. Барнаул, Россия (1)

Диагностический Центр Алтайского Края, г. Барнаул, Россия (2)

Городская больница №5, г. Барнаул, Россия (3)

Обоснование. Тромбоз глубоких вен нижних конечностей (ТГВНК) - значимая причина смертности и инвалидизации населения в мире. Однако, течение и распространенность ТГВНК в зависимости от содержания D-димеров и С-реактивного белка (СРБ) в остром периоде на фоне лечения недостаточно изучены.

Цель. Изучить отношение шансов (ОШ) развития ТГВНК, характер поражения и течение тромбоза в зависимости от содержания D-димеров и СРБ в остром периоде на фоне антикоагулянтной терапии (АКТ).

Материалы и методы. В исследование включено 62 пациента с ТГВНК. В первую группу вошли 37 пациентов с проксимальным тромбозом (27 мужчин и 10 женщин), во вторую группу - 25 больных с дистальным тромбозом (14 мужчин и 11 женщин). В контрольную группу включено 74 относительно здоровых лицам (45 мужчин и 29 женщин). На 1-3, 5-7 и 12-14 сутки госпитализации у больных наряду со стандартными показателями крови количественно определялось содержание D-димеров и СРБ.

Результаты. У больных в остром периоде в течение 12-14 суток с проксимальным и дистальным ТГВНК среднее содержание D-димеров и СРБ в сыворотке крови статистически значимо выше, чем у здоровых лиц. Средние значения D-димеров и СРБ при проксимальном тромбозе статистически значимо выше по сравнению с дистальным тромбозом. Установлена умеренная корреляционная взаимосвязь между содержанием D-димеров и СРБ в сыворотке на 5-7 и 12-14 сутки от госпитализации у больных с проксимальным ТГВНК на фоне АКТ, а у больных с дистальным ТГВНК - на 1-3 и 12-14 сутки.

Выводы. Увеличение содержания D-димеров и СРБ в сыворотке крови ассоциировано с увеличением отношения шансов развития проксимального и дистального ТГВНК. Содержание D-димеров в сыворотке более 500 нг/мл ассоциировано с увеличением ОШ развития проксимального и дистального ТГВНК в 36,5 и 35,9 раза, соответственно, а увеличение уровня СРБ в сыворотке более 10 мг/л - в 16,8 и 8,7 раза, соответственно. Определение содержания D-димеров и СРБ у больных с ТГВНК позволяет оценить его течение и прогноз, а также эффективность АКТ в остром периоде.

Ключевые слова: проксимальный и дистальный тромбоз глубоких вен нижних конечностей, D-димеры, C-реактивный белок, воспаление, течение венозного тромбоза, острый период.

\title{
CLINICAL COURSE OF DEEP VENOUS THROMBOSIS OF LOWER LIMBS IN ACUTE PERIOD WITH UNDERLYING ANTICOAGULANT THERAPY DEPENDING ON CONCENTRATION OF D-DIMERS AND C-REACTIVE PROTEIN
}

\author{
(C) A.S. Petrikov ${ }^{1,2}$, D.V. Dudin ${ }^{1,3}$, L.N. Popkova ${ }^{3}$, I.V. Volodin ${ }^{1,3}$, Ya.N. Shoikhet ${ }^{1,3}$
}

Altai State Medical University, Barnaul, Russia (1)

Diagnostic Center of Altai Territory, Barnaul, Russia (2)

Municipal Hospital №5, Barnaul, Russia (3) 
Background. Deep venous thrombosis of the lower limbs (DVTLL) is a significant cause of death and disability of the world population. However, the course and prevalence of DVTLL depending on the concentration of D-dimers and C-reactive proteins (CRP) in the acute period with the underlying treatment are not completely studied.

Aim. To study the odd ratio for development of DVTLL, the character of damage and clinical course of thrombosis depending on the concentration of D-dimers and CRP in the acute period with use of anticoagulant therapy (ACT).

Materials and methods. The research included 62 patients with DVTLL. The first group included 37 patients with proximal thrombosis ( 27 men and 10 women), the second group - 25 patients with distal thrombosis (14 men and 11 women). The control group consisted of 74 relatively healthy individuals (45 men and 29 women). On the $1^{\text {st }}-3^{\text {d }}, 5^{\text {th }}-7^{\text {th }}$ and $12^{\text {th }}-14^{\text {th }}$ days of hospitalization, along with standard blood indices, concentration of D-dimers and CRP were determined.

Results. In patients in the acute period of proximal and distal DVTLL, the average concentrations of D-dimers and CRP with in 12-14 days were statistically significantly higher than in healthy individuals. The average values of D-dimers and CRP in proximal thrombosis were statistically significantly higher than in distal thrombosis. A moderate correlation relationship was established between concentration of D-dimers and CRP in blood serum on the $5^{\text {th }}-7^{\text {th }}$ and $12^{\text {th }}$ $14^{\text {th }}$ days of hospitalization in patients with proximal DVTLL, and on the $1^{\text {st }}-3^{\mathrm{d}}$ and $12^{\text {th }}-14^{\text {th }}$ days in patients with distal thrombosis.

Conclusions. Increase in the concentration of D-dimers and CRP in blood serum was associated with increase in OR for development of proximal and distal DVTLL. Increase in the concentration of D-dimers in serum above $500 \mathrm{ng} / \mathrm{ml}$ was associated with 36.5- and 35.9-fold increase in OR for development of proximal and distal DVTLL, respectively, and increase in the level of CRP in serum above $10 \mathrm{mg} / \mathrm{L}$ - with 16.8- and 8.7- fold increase in OR, respectively. Determination of the concentration of D-dimers and CRP in patients with DVTLL permits to evaluate its course, prognosis and also effectiveness of ACT in the acute period.

Keywords: proximal and distal deep venous thrombosis of lower limbs, $D$-dimers, $C$-reactive protein, inflammation, clinical course of venous thrombosis, acute period.

Развитие тромбоза глубоких вен нижних конечностей (ТГВНК) остается существенной проблемой современной медицины и является одной из значимых причин смертности и инвалидизации населения [1-3]. В связи с этим своевременная диагностика ТГВНК, позволяющая определить характер заболевания и возможный риск для больного, приобретает первостепенное значение.

В настоящее время в диагностике ТГВНК наряду с инструментальнымии ультразвуковыми методами широко применяются лабораторные методы, среди которых существенное значение имеет определение D-димеров [3-5].

Известно, что D-димеры являются продуктом распада фибрина и неотъемлемым показателем активации системы коагуляционного гемостаза, а его высокая концентрация в плазме крови - непременный показатель тромботического состояния [6]. Содержание D-димеров может являться прогностическим признаком течения венозного тромбоза [7].

В то же время, наряду с разнонаправленными нарушениями в системе гемостаза, значительную роль в патогенезе развития ВТЭО многие исследователи отводят локальному и системному воспалению [8-10]. Наиболее значимым маркером воспалительного ответа считается Среактивный белок (СРБ), относящийся к группе белков острой фазы [10]. Е.А. Thomas, M.J. Cobby с соавт. доказали, что СРБ является высокочувствительным и надежным острофазным белком, способствующим установлению диагноза ТГВНК [11]. Было установлено, что использование СРБ в диагностике венозного тромбо- 
за имеет 100\%-ную чувствительность (95\% ДИ 78-100\%) при специфичности метода 52\% (95\% ДИ 34-70\%). Согласно современным представлениям, содержание СРБ может отражать локальное воспаление в интиме сосуда и проспективно определять риск развития сосудистых осложнений. Его повышенные концентрации в сыворотке крови также могут патологически воздействовать на эндотелий и приводить к его деструкции, утрате тромборезистентности, а также потери способности противостоять агрегации тромбоцитов и фибринообразованию [12].

В последние годы появились работы, касающиеся определения содержания белков острой фазы воспаления и маркеров коагуляционного гемостаза $[13,14]$, а также оценке их ассоциативных взаимосвязей при ТГВНК в остром периоде $[7,12,15]$. Однако вопрос динамики изменения D-димеров и СРБ в остром периоде в зависимости от распространенности тром-ботического процесса остается недостаточно изученным. Оценка взаимосвязей гемостатических и воспалительных реакций у больных с ТГВНК в остром периоде может позволить выявить отдельные патогенетические механизмы в развитии венозного тромбоза и, на наш взгляд, поможет определить прогностическое течение заболевания на фоне изученных клинико-лабораторных маркеров и АКТ.

Bсе вышеперечисленное явилось предпосылкой для определения количественного содержания D-димеров и СРБ в сыворотке крови в остром периоде, изучения взаимосвязей между ними и их ассоциативного влияния на течение ТГВНК на фоне лечения.

\section{Цель исследования}

Изучить отношение шансов развития ТГВНК, характер поражения и течение венозного тромбоза в зависимости от содержания D-димеров и СРБ в остром периоде на фоне антикоагулянтной терапии.

\section{Материалы и методы}

В сравнительное проспективное исследование с ноября 2015 по май 2017 года были включены 62 пациента с доку- ментально подтвержденным ТГВНК в возрасте от 25 до 69 лет (средний возраст

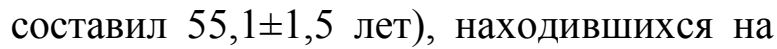
лечении в отделении сосудистой хирургии КГБУЗ «Городская больница №5, г. Барнаул» на клинической базе кафедры факультетской и госпитальной хирургии с курсом хирургии ДПО ФГБОУ ВО АГМУ МЗ РФ. В зависимости от характера поражения венозного русла, больные были рандомизированы на 2 группы. В первую группу вошли 37 пациентов - 27 мужчин $(73,0 \%)$ и 10 женщин $(27,0 \%)$ с проксимальным ТГВНК (средний возраст 55,9 $\pm 1,8$ лет). Вторую группу составили 25 больных14 мужчин $(56,0 \%)$ и 11 женщин $(44,0 \%)$ с дистальным тромбозом глубоких вен (средний возраст 53,9 $\pm 2,6$ года). Статистически значимых различий между анализируемыми группами больных по полу и возрасту выявлено не было (p>0,05).

$\mathrm{y}$ пациентов первой группы изолированный проксимальный тромбоз диагностирован у 30 больных $(81,1 \%)$, сочетание ТГВНК с ТЭЛА было выявлено у 6 больных (16,2\%), а сочетание стромбозом поверхностных вен (ТПВ) - у 1 больного $(2,7 \%)$ (табл. 1). У 18 больных первой группы преобладали протяженные тромбозы бедренной вены в сочетании с поражением подколенной и берцовых вен (48,7\%). У 13 больных выявлен тромбоз подвздошнобедренно-подколенно-берцового сегмента $(35,1 \%)$, а у 6 больных $(16,2 \%)$ - подвздошно-бедренно-подколенный флеботромбоз.

Во второй группе изолированный дистальный ТГВНК был выявлен у 20 больных (80,0\%), сочетание дистального ТГВНК с ТЭЛА - у 2 больных (8,0\%), а сочетание с ТПВ - у 3 больных (12,0\%). Тромбоз с поражением подколенно-берцового сегмента был диагностирован у 18 больных (72,0\%), а изолированное поражение берцового сегмента - у 7 больных $(28,0 \%)$.

Критерии включения: тромбоз глубоких вен нижних конечностей, документально подтвержденный при выполнении ультразвукового ангиосканирования (УЗАС), возраст от 25 до 69 лет, длительность заболевания не более 14 суток. 
Критерии исключения: онкологические заболевания, острые инфекции, скелетные травмы и переломы, оперативные вмешательства, длительная иммобилизация, авиаперелеты, возраст моложе 25 лет и старше 69 лет, наличие противопоказаний к применению антикоагулянтной терапии (АКТ), тяжелые сопутствующие заболевания почек, печени и сердца в стадии декомпенсации.

Характер клинических проявлений у больных с ТГВНК

Таблица1

\begin{tabular}{|l|c|c|c|c|c|}
\hline \multirow{2}{*}{ Характер клинических проявлений } & \multicolumn{2}{|c|}{$\begin{array}{c}\text { Первая группа } \\
(\mathrm{n}=37)\end{array}$} & \multicolumn{2}{c|}{$\begin{array}{c}\text { Вторая группа } \\
(\mathrm{n}=25)\end{array}$} & \multirow{2}{*}{$\mathrm{p}>$} \\
\cline { 2 - 5 } & абс. число & $\%$ & абс. число & $\%$ & \\
\hline Изолированный ТГВНК & 30 & 81,1 & 20 & 80,0 & 0,05 \\
\hline ТГВНК + ТЭЛА & 6 & 16,2 & 2 & 8,0 & 0,05 \\
\hline ТГВНК + ТПВ & 1 & 2,7 & 3 & 12,0 & 0,05 \\
\hline Всего: & 37 & 100,0 & 25 & 100,0 & - \\
\hline
\end{tabular}

По методу случай - контроль была сформирована контрольная группа, в которую было включено 74 относительно здоровых лица, без признаков каких-либо заболеваний (45 мужчин и 29 женщин) в возрасте от 23 до 67 лет (средний возраст составил 52,2 $\pm 1,7$ года). Критериями включения являлись: отсутствие острых сосудистых событий в анамнезе (венозного или артериального тромбоза, ТЭЛА, инфаркта миокарда, инсульта и др.), отсутствие патологии со стороны бронхолегочной и сердечно-сосудистой систем, заболеваний суставов, онкологических заболеваний, скелетных травм и длительной иммобилизации. Статистически значимых различий по полу и возрасту между исследуемыми группами больных и контрольной группой выявлено не было ( $>>0,05)$.

При поступлении в стационар больным наряду с общепринятыми клиниколабораторными анализами крови (общий анализ с лейкоцитарной формулой, биохимический анализ, АПТВ, МНО, ПТИ, РФМК, фибриноген, общий анализ мочи) по стандартным описанным методикам на $1-3,5-7$ и 12-14 сутки госпитализации осуществлялся забор крови из кубитальной вены для количественного определения содержания D-димеров и СРБ.

Определение уровня D-димеров в сыворотке крови осуществлялось хемилюминесцентным двух стадийным иммуноферментным методом на автоматическом коагулометре Instrumentation Laboratory ACL Elite Pro (USA) с использованием реактивов «D-Dimer, Hemos IL». Оценка концентрации C-реактивного белка в сыворотке крови осуществлялось иммунотурбидиметрическим методом на автоматическом биохимическом анализаторе Sapphire 400 (Hirose Electronic System, Japan) с применением набора реагентов СРБ - Витал фирмы DAC - Spectro Med. Среднее содержание $\mathrm{D}$-димеров в сыворотке в контрольной группе составило 143,2 $\pm 9,2$ нг/мл, а содержание СРБ - 1,4 $\pm 0,2$ мг/л (табл. 2).

В остром периоде лечение больных осуществлялось согласно российским клиническим рекомендациям [5]. Всем больным назначался нефракционированный гепарин (НФГ) в качестве стартового препарата. В дальнейшем 8 больных (12,9\%) были переведены на антагонисты витамина К (АВК), а 54 больных $(87,1 \%)$ - на новые пероральные антикоагулянты (НПОАК). В первой группе 6 больным (16,2\%) осуществлен подбор дозы варфарина, 29 больных $(78,4 \%)$ с 5-х суток были переведены на прием дабигатрана этексилата (ДЭ) по 150 мг 2 раза в день, а 2 больным $(5,4 \%)$ назначен ривароксабан. Во второй группе варфарин назначен 2 больным $(8,0 \%)$, ДЭ - 21 больному $(84,0 \%)$ и ривароксабан - 2 больным $(8,0 \%)$. Статистически значимых различий с учетом применяемого препарата в анализируемых группах установлено не было. 
Статистическая обработка полученных данных осуществлялась с использованием лицензионных программ Microsoft Office и Statistica, version 10 (США), включавших оценку достоверности различия двух сравниваемых групп данных для параметрических вариационных рядов - критерий t Стьюдента, для дитохомных (качественных) данных - критерий z (Фишера), a также расчет коэффициента корреляции Пирсона (r). Для оценки нормальности распределения применялась визуальная оценка частотного распределения (по гистограмме и графику нормальности) с последующим использованием критерия Шапиро-Уилка. Статистически значимыми различия принимались при $\mathrm{p}<0,05$.

\section{Результаты и их обсуждение}

Установлено, что среднее содержание СРБ и D-димеров у больных с ТГВНК и ТЭЛА в остром периоде как среди пациентов с проксимальным, так и дистальным тромбозом было статистически значимо выше, чем в контрольной группе (табл. 2). Среднее содержание D-димеров у боль- ных первой группы на 1-3 сутки от госпитализации было статистически значимо выше, чем в контрольной группе на 2666 нг/мл $(\mathrm{p}<0,01)$, на 5-7 сутки - на 2188 нг/мл ( $<<0,01)$, а на 12-14 сутки - на 1371 нг/мл $(\mathrm{p}<0,01)$. У больных второй группы концентрация D-димеров на 1-3 сутки от госпитализации была статистически значимо выше средних значений контрольной группы на 1421 нг/мл $(\mathrm{p}<0,01)$, на 5-7 сутки - на 1043 нг/мл $(\mathrm{p}<0,01)$, а на 12-14 сутки - на 305 нг/мл (p<0,01).

При внутригрупповом сравнении установлено, что у больных с проксимальным ТГВНК на фоне АКТ на 12-14 сутки среднее содержание D-димеров было статистически значимо ниже на 1295 нг/мл $(\mathrm{p}<0,01)$ по сравнению с 1-3 сутками и на 817 нг/мл по сравнению с 5-7 сутками ( $<<0,001)$. Также отмечено статистически значимое снижение среднего содержания D-димеров на 12-14 сутки у пациентов с дистальным ТГВНК на 1116 мг/мл $(\mathrm{p}<0,01)$ по сравнению с 1-3 сутками и на 378 нг/мл $(\mathrm{p}<0,05)$ по сравнению с 5-7 сутками.

Таблица 2

\section{Динамика содержания D-димеров и СРБ у больных с ТГВНК в остром периоде}

\begin{tabular}{|c|c|c|c|c|c|c|}
\hline \multicolumn{7}{|c|}{ Динамика содержания D-димеров (нг/мл) } \\
\hline $\begin{array}{c}\text { период } \\
\text { наблюдения }\end{array}$ & $\begin{array}{c}\text { первая группа } \\
(\mathrm{n}=37)\end{array}$ & $\begin{array}{c}\text { вторая группа } \\
(\mathrm{n}=25)\end{array}$ & $\begin{array}{c}\text { контрольная группа } \\
(\mathrm{n}=74)\end{array}$ & $\mathrm{p}_{1-2}<$ & $\mathrm{p}_{1-\mathrm{\kappa}}<$ & $\mathrm{p}_{2-\mathrm{K}}<$ \\
\hline $1-3$ сутки & $2809 \pm 346,7$ & $1564 \pm 202,8$ & \multirow{6}{*}{$143,2 \pm 9,3$} & 0,01 & 0,01 & 0,01 \\
\hline 5-7 сутки & $2331 \pm 391,3$ & $1186 \pm 200,5$ & & 0,01 & 0,01 & 0,01 \\
\hline 12-14 сутки & $1514 \pm 221,3$ & $448 \pm 79,5$ & & 0,01 & 0,01 & 0,01 \\
\hline $\mathrm{p}_{(1-3)}-\mathrm{p}_{(5-7)}$ & $>0,05$ & $<0,05$ & & \multirow{3}{*}{-} & \multirow{3}{*}{ 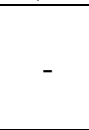 } & \multirow{3}{*}{-} \\
\hline $\mathrm{p}_{(1-3)}-\mathrm{p}_{(12-14)}$ & $<0,01$ & $<0,01$ & & & & \\
\hline $\mathrm{p}_{(5-7)}-\mathrm{p}_{(12-14)}$ & $<0,01$ & $<0,01$ & & & & \\
\hline \multicolumn{7}{|c|}{ динамика содержания С-реактивного белка (мг/л) } \\
\hline $\begin{array}{c}\text { период } \\
\text { наблюдения }\end{array}$ & $\begin{array}{c}\text { первая группа } \\
(\mathrm{n}=37)\end{array}$ & $\begin{array}{c}\text { вторая группа } \\
(\mathrm{n}=25)\end{array}$ & $\begin{array}{c}\text { контрольная группа } \\
(\mathrm{n}=74)\end{array}$ & $\mathrm{p}_{1-2}<$ & $\mathrm{p}_{1-\kappa}<$ & $\mathrm{p}_{2-\mathrm{K}}<$ \\
\hline $1-3$ сутки & $58,0 \pm 6,4$ & $28,4 \pm 7,4$ & \multirow{6}{*}{$1,4 \pm 0,2$} & 0,01 & 0,01 & 0,01 \\
\hline 5-7 сутки & $33,0 \pm 7,1$ & $14,4 \pm 2,6$ & & 0,01 & 0,01 & 0,01 \\
\hline 12-14 сутки & $17,2 \pm 4,3$ & $6,0 \pm 0,7$ & & 0,01 & 0,01 & 0,01 \\
\hline $\mathrm{p}_{(1-3)}-\mathrm{p}_{(5-7)}$ & $<0,01$ & $<0,01$ & & & \multirow{3}{*}{ - } & \multirow{3}{*}{ - } \\
\hline $\mathrm{p}_{(1-3)}-\mathrm{p}_{(12-14)}$ & $<0,01$ & $<0,01$ & & - & & \\
\hline $\mathrm{p}_{(5-7)}-\mathrm{p}_{(12-14)}$ & $<0,01$ & $<0,01$ & & & & \\
\hline
\end{tabular}

На 1-3 сутки от госпитализации содержание D-димеров у больных первой группы было статистически значимо выше, чем у больных второй группы на 1245 нг/мл ( $<<0,01)$, на 3-5 сутки - на 1145 нг/мл ( $<0,01)$, а на 12-14 сутки - на 1066 нг/мл $(\mathrm{p}<0,01)$.

Среднее содержание СРБ у больных с проксимальным тромбозом группы на 1-3 сутки от госпитализации было статистиче- 
ски значимо выше, чем в контрольной группе на 56,6 мг/л (p<0,01), на 5-7 сутки - на $31,6 \mathrm{мг/л}(\mathrm{p}<0,01)$, а на 12-14 сутки - 15,8 мг/л $(\mathrm{p}<0,01)$. У больных с дистальным ТГВНК уровень СРБ на 1-3 сутки от госпитализации был статистически значимо выше контрольных данных на 27,0 мг/л (p<0,01), на 5-7 сутки - на 13,0 мг/л ( $<0,01)$, а на 12-

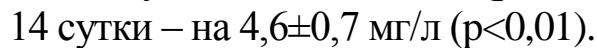

При внутригрупповом сравнении установлено, что у больных первой группы на фоне АКТ происходит статистически значимое снижение среднего содержания СРБ на 5-7 сутки на 25,0 мг/л $(\mathrm{p}<0,01)$, а на 12-14 сутки на 40,8 мг/л $(p<0,01)$ в сравнении с 1-3 сутками. Также отмечено статистически значимое снижение среднего содержания СРБ у пациентов с дистальным ТГВНК - на 14,0 мг/л $(\mathrm{p}<0,05)$ на 5-7 сутки, а на 12-14 сутки - на 22,4 мг/л $(\mathrm{p}<0,01)$ по сравнению с 1-3 сутками.

На 1-3 сутки от госпитализации содержание СРБ у больных первой группы было статистически значимо выше, чем у больных второй группы на 29,6 мг/л ( $<<0,01)$, на 3-5 сутки - на 18,6 мг/л $(\mathrm{p}<0,01)$, а на 12-14 сутки - на 11,2 нг/мл (p<0,01).

Таким образом, среднее содержание $\mathrm{D}$-димеров и СРБ в сыворотке крови у больных с проксимальным ТГВНК было статистически значимо выше, чем при дистальном венозном тромбозе, что свидетельствует о более значимом и протяженном поражении венозного русла.

Корреляционный анализ установил наличие в первой группе ассоциативных взаимосвязей средней силы между содержанием D-димеров и СРБ на 5-7 сутки $(\mathrm{r}=0,55 ; \mathrm{p}=0,012)$ и на $12-14$ сутки $(\mathrm{r}=0,46$; $\mathrm{p}=0,0042)$. У больных второй группы была установлена корреляционная взаимосвязь средней силы между содержанием D-димеров и СРБ на 1-3 сутки ( $\mathrm{r}=0,58 ; \mathrm{p}=0,0092)$ и на $12-14$ сутки ( $\mathrm{r}=0,53 ; \mathrm{p}=0,0204)$.

В остром периоде у больных ТГВНК на фоне АКТ установлена тенденция к снижению как среднего содержания Dдимеров, так и средней концентрации СРБ на 5-7 и 12-14 сутки по сравнению с исходными показателями $(\mathrm{p}<0,01)$. В первой группе на 12-14 сутки синхронное снижение содержания D-димеров и СРБ наблюдалось у 27 больных (73,0\%), снижение одного показателя - у 8 больных $(21,6 \%)$, a синхронное повышение D-димеров и СРБ отмечено лишь у 2 больных (5,4\%). Из этих двух больных на 13-е сутки от ТЭЛА умер один больной в возрасте 45 лет с острым левосторонним окклюзионным бедренно-подколенно-берцовым флебо-тромбозом, который был переведен на ABК (2,7\%). У него на фоне лечения отмечался значительный рост содержания СРБ на 5-7 и 12-14 сутки (более 100 мг/л), при этом уровень D-димеров на протяжении всего срока госпитализации был резко повышен (более 7500 нг/мл).

Во второй группе на 12-14 сутки синхронное снижение содержания Dдимеров и СРБ наблюдалось у 23 больных $(92,0 \%)$, снижение D-димеров на фоне роста СРБ - у 1 больного (4,0\%), а синхронное повышение D-димеров и СРБ лишь у 1 больной в возрасте 35 лет (4\%). $\mathrm{У}$ нее на протяжении всего острого периода сохранялся высокий уровень СРБ (более 50 мг/л) и D-димеров (более 2000 нг/мл). Пациентка получала варфарин в дозе 5 мг/сут. Спустя 4 месяца после выписки на фоне приема варфарина больная была госпитализирована повторно в связи с развитием острого рецидивирующего левостороннего бедренно-подколенно-берцового флеботромбоза.

Изучено влияние различных уровней $\mathrm{D}$-димеров и СРБ в сыворотке крови на отношение шансов (ОШ) развития ТГВНК. Установлено, что содержание Dдимеров в сыворотке крови в диапазонах до 250 нг/мл не сопровождалось увеличением отношения шансов развития как дистального [OR=0,022; 95\% CI: 0.001$0.087, \mathrm{p}>0,05]$, так и проксимального [OR=0,007; 95\% CI: 0.001-0.055, p >0,05] ТГВНК. Концентрация D-димеров от 251 до 500 нг/мл также не влияла на ОШ развития дистального [OR=0,207; 95\% CI: 0.026-1.676, $\mathrm{p}>0,05]$ и проксимального [OR=0,132; 95\% CI: 0.017-1.055, p>0,05] тромбоза, тогда как повышение содержа- 
ния D-димеров более 500 нг/мл было ассоциировано с увеличением ОШ развития дистального тромбоза в 35,9 раза [OR=35,9; 95\% CI: 9.11-141.17, $\mathrm{p}<0,05]$, a проксимального тромбоза в 36,5 раза [OR=36,5; 95\% CI: 9.27-143.3, p<0,05].

Выявлено, что содержание СРБ в сыворотке до 5,0 мг/л не сопровождалось увеличением отношения шансов развития дистального [OR=0,104; 95\% CI: 0.382$6.735, \mathrm{p}>0,05]$ и проксимального ТГВНК [OR=0,021; 95\% CI: 0.721-3.774, $\mathrm{p}>0,05]$. Концентрация СРБ в диапазоне от 5,01 до 10,0 мг/л также не влияла на увеличение ОШ развития дистального $[\mathrm{OR}=1,612$; 95\% CI: 0.133-37.260, p>0,05] и проксимального тромбоза $[\mathrm{OR}=1,672 ; 95 \% \mathrm{CI}$ : 0.251-33.071, $\mathrm{p}>0,05]$, тогда как содержание СРБ в сыворотке крови более 10,0 мг/л ассоциировано с ОШ развития дистального тромбоза в 8,7 раза $[\mathrm{OR}=8,7$; 95\% CI: 4.031-18.576, p<0,05], а проксимального тромбоза в 16,8 раза $[\mathrm{OR}=16,8$; 95\% CI: 5.592-50.545, $\mathrm{p}<0,05]$.

Таким образом, увеличение содержания D-димеров в сыворотке крови более 500 нг/мл ассоциировано с увеличением ОШ развития как дистального, так и проксимального ТГВНК в 35,9 и 36,5 раза, соответственно. Увеличение концентрации СРБ более 10,0 мг/л ассоциировано с увеличением ОШ развития дистального тромбоза в 8,7 раза, а проксимального тромбоза - в 16,8 раза.

\section{Выводы}

Установлено, что у больных с проксимальным и дистальным ТГВНК в остром периоде в течение 12-14 суток среднее содержание D-димеров и СРБ в сыворотке крови статистически значимо выше, чем у здоровых лиц. При этом в остром периоде средние значения D-димеров и СРБ при проксимальном тромбозе стати-

\section{Литература}

1. Kearon C., Akl A.E., Comerota A.J., et al. Antithrombotic Therapy for VTE Disease.CHEST journal // Official publication of the American college of chest physician. 2016. Vol. 149. P. 315-352.

2. Kahn S.R., SpringmannV., Schulman S., et стически значимо выше по сравнению с дистальным тромбозом.

Имеется умеренная корреляционная взаимосвязь между содержанием D-димеров и СРБ в сыворотке на 5-7 и 12-14 сутки от госпитализации у больных с проксимальным ТГВНК, на 1-3 и 12-14 сутки у больных с дистальным ТГВНК на фоне АКТ.

Применение в остром периоде адекватной АКТ, сопровождающейся синхронным снижением содержания D-димеров и СРБ к 12-14 суткам от момента госпитализации свидетельствует о благоприятном течении ТГВНК. В то же время нарастание лабораторных маркеров на 5-7 и 12-14 сутки на фоне применения антикоагулянтов, в частности D-димеров и СРБ, может рассматриваться как прогностически неблагоприятный признак течения ТГВНК с развитием летального исхода или прогрессированием тромбоза.

Установлено, что содержание Dдимеров в сыворотке более 500 нг/мл ассоциировано с увеличением ОШ развития проксимального и дистального ТГВНК в 36,5 и 35,9 раза, соответственно. Увеличение уровня СРБ в сыворотке более $10 \mathrm{мг/л}$ ассоциировано с увеличением ОШ развития проксимального и дистального тромбоза в 16,8 и 8,7 раза, соответственно.

Определение содержания D-димеров и СРБ у больных с ТГВНК позволяет оценить его течение и прогноз, а также эффективность АКТ в остром периоде.

Дополнительная информация

Конфликт интересов: отсутствует.

Источники финансирования. Исследование не имело спонсорской поддержки.

Участие авторов:

Концепция и дизайн исследования - А.П., Д.Д. Сбор и обработка материала - А.П., Д.Д., Л.П., И.В.

Статистическая обработка - А.П., Д.Д.

Написание текста - А.П., Д.Д.

Редактирование - А.П., Я.Ш.

al. Management and adherence to VTE treatment guidelinesin a national prospective cohort study in the Canadian outpatient setting. The Recovery Study // Thrombosis and Haemostasis. 2012. Vol. 108(3). P. 493-498.

3. Андрияшкин А.В., Арутюнов Г.П., Бритов А.Н., и др. Российские клинические 
рекомендации по диагностике, лечению и профилактике венозныхтромбоэмболических осложнений (ВТЭО) // Флебология. 2015. Вып. 2. Т. 4, №2. С. 10-17.

4. Potu K.C., Ketineni S., Lamfers R.A. Primer on Diagnostic and Financial Implications of D-dimer Testing // SD Med. 2016. №69(9). P. 414-417.

5. Jezovnic M.K., Poredos P. Idiopathic venous thrombosis is related to systemic inflammatory response and to increased levels of circulating markers of endothelial dysfunction // International Angiology. 2010. Vol. 29, №3. P. 226-231.

6. Reber G., de Moerloose P. Standardization of D-dimer testing. In: Quality in laboratory hemostasis and thrombosis. Willey-Blackwell, Sheffield, UK. 2009. Р. 99-109.

7. Петриков А.С., Шойхет Я.Н., Дудин Д.В. Течение тромбоза глубоких вен и тромбоэмболии легочной артерии в остром периоде в зависимости от содержания Dдимеров и C-реактивного белка на фоне лечения // Медицинский вестник юга России. 2017. №3. С. 78-79.

8. Wang M.F., Yang L.H., Yang X.L., et al. Correlation of inflammatory marker and coagulation factors with deep vein thrombosis // Zhongguo Shi Yan Xue Ye Xue Za Zhi. 2010. Vol. 18, №3. P. 753-756.

9. Lippi G., Favaloro E.J., Montagnana M., et al. C-reactive protein and venous thromboembolism: causal or casual association? // Clinical Chemistry and Laboratory Medicine. 2010. Vol. 48(12). P. 1693-1701.

10. Kunutsor S.K., Seidu S., Blom A.W., et al. Serum C-reactive protein increases the risk of venous thromboembolism: a prospective study and meta-analysis of published prospective evidence // European Journal of Epidemiology. 2017. Vol. 32. P. 657-667.

11. Thomas E.A., Cobby M.J., Rhys Davies E., et al. Liquid crystal thermography and $\mathrm{C}$ reactive protein in the detection of deep venous thrombosis // J.T.B.M.J. 1989. Vol. 299, P. 951-952.

12. Петриков А.С., Шойхет Я.Н., Белых В.И. Многофакторный анализ риска тромбозов вен нижних конечностей, тромбоэмболии легочной артерии на основе маркеров воспаления, гемостаза и эндотелиальной дисфункции. Барнаул: Алгу, 2015.

13. Zacho J., Tybjaerg-Hansen A., Nordestgaard B.G. C-reactive protein and risk of venous thromboembolism in the general population // Arteriosclerosis, Thrombosis and Vascular Biology. 2010. Vol. 30(8). P. 1672-1678.

14. Folsom A.R., Lutsey P.L., Astor B.C., et al. $\mathrm{C}$-reactive protein and venous thromboembolism. A prospective investigation in the ARIC cohort // Thrombosis and Haemostasis. 2009. Vol. 102(4). P. 615-619.

15. Olson N.C., Cushman M., Lutsey P.L., et al. Inflammation markers and incident venous thromboembolism: the reasons for geographic and racial differences in stroke (REGARDS) cohort // Thrombosis and Haemostasis. 2014. Vol. 12. P. 1993-2001.

\section{References}

1. Kearon C, Akl A, Comerota A, et al. Antithrombotic Therapy for VTE Disease. CHEST journal. Official publication of the American college of chest physician. 2016; 149:315-52. doi:10.1016/j.chest.2015.11.026.

2. Kahn S, Springmann V, Schulman S, et al. Management and adherence to VTE treatment guidelinesin a national prospective cohort study in the Canadian outpatient setting. The Recovery Study. Thrombosis and Haemostasis. 2012;108(3):493-8. doi:10.1160/th 12-03-0169.

3. Andrijashkin AV, Arutjunov GP, Britov AN, et al. Rossiyskiye klinicheskiye rekomendatsii po diagnostike, lecheniyu i profilaktike venoznykh tromboembolicheskikh oslozhneniy (VTEO). Flebologiya. 2015;4(2):10-7. (In Russ).

4. Potu KC, Ketineni S, Lamfers RA. Primer on Diagnostic and Financial Implications of D-dimer Testing. South Dakota journal of medicine. 2016;69(9):414-17.

5. Jezovnic $\mathbf{M}$, Poredos $\mathrm{P}$. Idiopathic venous thrombosis is related to systemic inflammatory response and to increased levels of circulating markers of endothelial dysfunction. International Angiology. 2010;29(3):226-31.

6. Reber G, de Moerloose P. Standardization of D-dimer testing. In: Quality in laboratory hemostasis and thrombosis. Willey-Blackwell, Sheffield, UK; 2009. P. 99-109.

7. Petricov AS, Shoykhet YaN, Dudin DV. Techeniye tromboza glubokikh ven i tromboembolii legochnoy arterii $\mathrm{v}$ ostrom periode $\mathrm{v}$ zavisimosti ot soderzhaniya $\mathrm{D}$ dimerov i C-reaktivnogo belka na fone lecheniya. Medical Herald of the South of Russia. 2017;3:78-9. (In Russ).

8. Wang M, Yang L, Yang X, et al. Correlation of inflammatory marker and coagulation factors with deep vein thrombosis. Zhongguo Shi Yan Xue Ye Xue Za Zhi. 2010;18(3):753-6. 
9. Lippi G, Favaloro E, Montagnana M, et al. C-reactive protein and venous thromboembolism: causal or casual association? Clinical Chemistry and Laboratory Medicine. 2010; 48(12):1693-1701.doi:10.1515/CCLM.2010.335

10. Kunutsor S, Seidu S, Blom A, et al. Serum Creactive protein increases the risk of venous thromboembolism: a prospective study and meta-analysis of published prospective evidence. European Journal of Epidemiology. 2017;32: 657-67. doi:10.1007/s10654-017-0277-4.

11. Thomas E, Cobby M, Rhys Davies E, et al. Liquid crystal thermography and $\mathrm{C}$ reactive protein in the detection of deep venous thrombosis. BMJ. 1989;299:951-2.

12. Petricov AS, Shoykhet YaN, Belyh VI. Mnogofaktornyy analiz riska trombozov ven nizhnikh konechnostey, tromboembolii legochnoy arterii na osnove markerov vospale- niya, gemostaza i endotelial'noy disfunktsii. Barnaul: AltSU; 2015. (In Russ).

13. Zacho J, Tybjaerg-Hansen A, Nordestgaard BG. C-reactive protein and risk of venous thromboembolism in the general population. Arteriosclerosis, Thrombosis and Vascular Biology. 2010;30(8):1672-78. doi: 10.1161/ATVBAHA.109.198473.

14. Folsom A, Lutsey P, Astor B, et al. C-reactive protein and venous thromboembolism. A prospective investigation in the ARIC cohort. Thrombosis and Haemostasis. 2009; 102(4): 615-9. doi:10.1160/TH09-04-0274.

15. Olson N, Cushman M, Lutsey P, et al. Inflammation markers and incident venous thromboembolism: the reasons for geographic and racial differences in stroke (REGARDS) cohort. Thrombosis and Haemostasis. 2014; 12:1993-2001. doi:10.1111/jth.12742.

\section{Информация об авторах [Authors Info]}

Петриков Алексей Сергеевич - доктор медицинских наук, профессор кафедры факультетской хирургии имени профессора И.И. Неймарка, госпитальной хирургии с курсом хирургии ДПО; Алтайский государственный медицинский университет; e-mail: petricov_alex@mail.ru

Alexey S. Petricov - MD, PhD, DSc, professor, Department of Departmental Surgery; Altai State Medical University; e-mail: petricov_alex@mail.ru

SPIN: 4612-6452; ORCID ID: 0000-0002-6501-3289

Дудин Денис Валерьевич - аспирант, ассистент кафедры факультетской хирургии имени профессора И.И. Неймарка, госпитальной хирургии с курсом хирургии ДПО; Алтайский государственный медицинский университет (автор, ответственный за переписку); e-mail: ya.denis-dudin@yandex.ru

Denis V. Dudin - PhD-student, assistant professor, Department of Departmental Surgery; Altai State Medical University (corresponding author); e-mail: ya.denis-dudin@yandex.ru

SPIN: 2219-5525; ORCID ID: 0000-0001-7557-9983

Попкова Любовь Ильинична - врач клинической лабораторной диагностики; КГБУЗ «Городская больница №5, г. Барнаул».

Lyubov I. Popkova - Clinical Pathologist, Krai Government-owned Publicly Funded Health Care Institution; City Hospital №5, Barnaul.

Володин Илья Владимирович - врач клинической лабораторной диагностики; КГБУЗ «Городская больница №5, г. Барнаул».

Ilya V. Volodin - Clinical Pathologist, Krai Government-owned Publicly Funded Health Care Institution; City Hospital №5, Barnaul.

Шойхет Яков Нахманович - член-корреспондент РАМН, доктор медицинских наук, профессор, заведующий кафедрой факультетской хирургии имени профессора И.И. Неймарка, госпитальной хирургии с курсом хирургии ДПО; Алтайский государственный медицинский университет; e-mail: starok100@mail.ru

Yakov N. Shoykhet - Corresponding Member, Russian Academy of Medical Sciences; MD, PhD, DSc, professor, Head of Department of Departmental Surgery; Altai State Medical University, e-mail: starok100@mail.ru

Цитировать: Петриков А.С., Дудин Д.В., Попкова Л.Н., Володин И.В., Шойхет Я.Н. Течение тромбоза глубоких вен нижних конечностей в остром периоде на фоне антикоагулянтной терапии в зависимости от содержания Dдимеров и С-реактивного белка // Наука молодых (Eruditio Juvenium). 2018. Т. 6, №2. С. 233-241.

To cite this article: Petrikov AS, Dudin DV, Popkova LN, Volodin IV, Shoikhet YaN. Clinical course of deep venous thrombosis of lower limbs in acute period with underlying anticoagulant therapy depending on concentration of D-dimers and C-reactive protein. Science of the young (Eruditio Juvenium). 2018;6(2):233-41.

Поступила / Received: 13.05 .2018

Принята в печать / Accepted: 01.06.2018 